\title{
Scientific realism with historical essences: the case of species
}

\section{Marion Godman ${ }^{1}$}

Received: 12 April 2018 / Accepted: 22 November 2018 / Published online: 17 December 2018 (C) The Author(s) 2018

\begin{abstract}
Natural kinds, real kinds, or, following J.S. Mill simply, Kinds, are thought to be an important asset for scientific realists in the non-fundamental (or "special") sciences. Essential natures are less in vogue. I show that the realist would do well to couple her Kinds with essential natures in order to strengthen their epistemic and ontological credentials. I argue that these essential natures need not however be intrinsic to the Kind's members; they may be historical. I concentrate on assessing the merits of historical essential natures in a paradigm case of Kinds in the non-fundamental sciences: species. I specify two basic jobs for essential natures: (1) offering individuation criteria, and (2) providing a causal explanation of the Kind's multiple projectable properties. I argue that at least in the case of species historical essences are fit for both tasks. The principled resistance to Kinds with historical essences should also be cleared.
\end{abstract}

Keywords Scientific realism $\cdot$ Historical essences $\cdot$ Species $\cdot$ Natural kinds $\cdot$ Path dependency $\cdot$ Essentialism

Before the Origin, scientists had sought the intrinsic purpose and meaning of taxonomic order. Darwin replied that the ordering reflects historical pathways pure and simple

Stephen Jay Gould, Evolution and the Triumph of Homology, or Why History Matters

Marion Godman

marion.godman@gmail.com

1 History and Philosophy of Science department, Cambridge University, Cambridge, UK 


\section{Introduction}

Natural kinds, real kinds, or, from now on following John Stuart Mill, simply, Kinds, are thought to be an important asset for scientific realists in the non-fundamental (or “special") sciences (Boyd 1991, 2010; Kornblith 1995; Wilson 1999; Snyder 2005; cf. Massimi 2014). Essential natures are less in vogue. In this paper, I will argue that the realist would do well to couple their Kinds with essential natures in order to strengthen their epistemic and ontological credentials. These essential natures need not however be intrinsic to the Kind's members; they may be historical.

My argument here will almost exclusively concern the case of species and the claim that historical essences can underpin these local claims of scientific realism. Although I will make some suggestive remarks along the way about how the morals about scientific realism and historical essences might generalize to other cases, a full exploration of the generalizability will have to wait for another occasion. ${ }^{1}$ This limited focus on species has some important advantages though.

First, there is good reason to think that a lot hangs on the issue of species since they often take center stage in discussions not only of biological Kinds, but also of Kinds more generally. Even Ian Hacking, no fan of natural kind talk, agrees that: "Biological species have long served as paradigms of natural kinds- they are (one feels) natural kinds if anything is" (2007, p. 234). So a successful treatment for the paradigm case of species should have more general implications as well.

Second, there is plenty of philosophical interest in the case of species in its own right. A dominant view holds that species lack essential natures. Yet a by now familiar response is that this does not refute essentialism of species altogether as they may have historical rather than intrinsic essential natures (Hull 1978; Griffiths 1999; Millikan 1999; Okasha 2002; Rieppel 2007; Ereshefsky 2014; for related arguments in biology see also Simpson 1951; Gould 1986; De Queiroz 1999). However as historical essences are relational to their members, they are thought to suffer from some significant epistemic and ontological shortcomings (Hull 1978; Okasha 2002; Elder 2008; Ellis 2011). The view therefore seems to come at a cost for scientific realists and other ontologically committed views about species. Hence, another aim of the paper is to counter the prevailing pessimism and skepticism associated with a historical essentialist view of species. By implication, my quarrel will not primarily be with intrinsic essentialism of species (Devitt 2008, 2010) - or only to the extent that it invokes skeptical claims against historical essences (cf. Godman and Papineau 2019).

\section{Scientific realism and the essential natures of kinds}

According to scientific realists, science aims and is able to uncover the true, or approximately true, organization of the world. That there is way in which the world is organized is the ontological part of scientific realism and that we aim and are able to access it

\footnotetext{
1 Although I tend to agree that scientific realism should be defended in a piecemeal fashion (see e.g. Kincaid 2000), I hope to provide some ideas for how similar arguments can be made from the historical essences of other non-fundamental or "special science" kinds in the work of Millikan (1999), Bach (2012) and Godman (2015, 2018).
} 
represents the epistemic component. Following Alexander Bird's recommendation, I believe a scientific realist should also include a condition of how true beliefs about the world are acquired (2007). It cannot be a matter of accidentally arriving at the true beliefs; if it is scientific knowledge we are concerned with, it must be acquired through a cumulative process of empirical investigation and theorizing. Done right, we might deem this process scientific progress.

Now, to be fair, many scientific instrumentalists and conventionalists can accept most if not all of the above. So usually the scientific knowledge distinctively asserted by realists concerns deeper posits or those commonly thought of as unobservables. But in the non-fundamental sciences, where induction rules the day, it is not the lack of observability that is the main issue. What tends to be the concern here is the empirical knowledge of a robust or objective basis for the categories used in inductive practice. ${ }^{2}$ The basic line of thought is the following: Realists will grant that the relevant scientific categories are often identified via observable features (not least in the case of species). However merely identifying instances that share some similar features-that also might only be so deceptively_is deemed insufficient for true scientific progress. Instead, it is the existence of an objective, robust or, if you will, mind-independent, basis for the categories with similar features, which may or may not be observable, that is at the heart of scientific realism.

I believe that it is this concern to defend our knowledge of the objective grounds for categorization that has, or at least should, motivate an enduring interest in essential natures. The most prominent plea for essential natures in the last decades is found in the work of Putnam (1975) and Kripke (1980). Although they did not focus on scientific realism per se, but on the semantic and modal implications of real essences, their concerns are often picked up or interpreted in light of scientific realist concerns (e.g. Churchland 1985). I here want to nominate two important epistemic roles-individuation and explanation-for essential natures of Kinds that are present in the work of Putnam and Kripke (but also to some extent in earlier thinkers like Aristotle and $\mathrm{Mill}^{3}$ ) that I believe serve the purposes of scientific realists.

\subsection{The individuating role of essences}

The first role for essential natures is to secure objective and robust membership criteria of Kinds. Putnam's famous argument was precisely that reference of Kind terms is secured by the existence of essential natures, such that the members of Kinds need neither be united by incidental superficial resemblances nor by whichever descriptions (or use) we happen to attach to Kind terms. Instead, an instance or individual receives its Kind membership in virtue of sharing an essential nature with other instances of the same Kind. For the realist such an individuation criteria for Kinds is crucial. It is what underpins the successful use of Kinds in our inferential practice since there are

\footnotetext{
2 Of course a scientific realist of the non-fundamental sciences does have the option of abandoning a thesis that relies on (real) Kinds or on entities. One may, for example, instead adopt a structural realism for these sciences (e.g. French 2011).

3 It is at least arguable that John Stuart Mill envisioned a "Kind-style" scientific realism although he did not assign essential natures to his Kinds (for some further discussion, see Boyd 1991; Millikan 1999; Hacking 2007).
} 
some real grounds for unifying different samples. This can also explain our relative success in extrapolating, generalizing, and in constructing taxonomies based on Kinds compared to those apparent categories which may only have superficial properties in common. Essential natures can also help establish inter-theoretic identities between scientific domains in the same or in different historical points of time. This is important if one wishes to counter arguments such as the pessimistic induction that aims to block the idea of scientific progress.

But, hold on. Along Lockean lines we might worry whether there really are essential natures - especially given that the track record of the categories used in the inductive sciences being a mixed bag of retention, revision, and removal. This is where it helps if the essential nature is known, since we then also have a better way of justifying our inductive practice. According to Kripke not only does our linguistic and inferential success hinge on there being robust grounds for individuating Kinds, we can also learn a posteriori what these grounds are: we discover that 'Water is $\mathrm{H}_{2} \mathrm{O}$ ' whereas previously we were in the dark about the cause of any semantic, inductive and taxonomic success. In fact, we can fit this into a (non-accidental) knowledge requirement that I, following Bird, suggested should be included in a scientific realism. That is, not only is a Kind's essence knowable a posteriori; typically there is some, and often a significant, scientific contribution and taxonomic revision involved in its "uncovering". 4

The scientific contribution in question is often simply equated with empirical investigation, but the contribution from theorizing should not be neglected. After all the a posteriori fact (or if you will, necessity ${ }^{5}$ ) that all samples of water have the molecular structure of $\mathrm{H}_{2} \mathrm{O}$ is one arrived at through considerable theoretical controversy in chemistry; yet is precisely the sort of achievement that a scientific realist must rely on in order to explain how both ignorance and failure in science is compatible with progress overall. Some folk taxonomies have in the past been ignorant but lucky (as in the case of water), while others have gone plain wrong (such as famously including whales in the category, Fish). But classificatory revisions in light of science have led to epistemic payoffs for our inductive practice (i.e. with knowledge of the essential natures we no longer project whale-type similarities on to all fish and vice versa and we also have a better understanding of the scope for our inferences about water). The possibility of a posteriori discovered essences does make some initial sense of this development where it is science itself that provides us with progressively more robust individuation conditions of the Kinds, thus modifying and improving on existing classifications, in terms of improving the scope and reliability of our inferences.

\footnotetext{
4 In contrast, Muhammed Ali Khalidi has suggested that it may be conceptually possible that we discover the essential —or in his terms most important properties - that both defines and explains the Kind's nature without further scientific work being required (2013, p. 55). But this conceptual possibility seems to me of little consequence for a scientific realist since they need the discovery of natural kind essences to be an epistemic accomplishment, to justify taxonomic and inductive practice, and as a starting point for making not-mere-luck arguments.

5 See Mallozzi (2018) and Godman et al. (under consideration) for a discussion of the modal consequences of the view.
} 


\subsection{The explanatory role of essences}

John Stuart Mill's contributions to theorizing about Kinds were lasting and, for the field, unusually uncontroversial. In his view, the scientific use of Kinds, as opposed to other concocted groups of individuals like White Horse, could be explained by Kinds supporting a comparably greater-or even an unlimited-quantity of generalizations (1872). Few would dispute that the comparable epistemic advantage of categories which afford multiple projectable features. It is less observed that Kinds are also epistemically valuable as groups with relevant variations within members. In the case of species, it has for instance been argued that any model of species cannot overlook polymorphic and other polytypic species that display significant variations amongst their members (Ereshefsky and Matthen 2005; Magnus 2011). Yet much of the polymorphic variation is systematic, heritable, and so gives rise to further projectable features amongst instances. Moreover members of different polytypic species also have many characteristics in common in Mill's original sense. In general intra-Kind variation is expected and should not undermine certain instances belonging to the same Kind. Thus the role for Kinds in supporting multiple projectable properties still stands, keeping in mind that there may also be both projectable and non-projectable variation amongst members.

Many are content to treat this multiple projectability as an unexplainable "brute fact" (Lewens 2012), "real pattern" (Dennett 1991), or "bare projectability" (Häggqvist 2005). However, I'd contend that scientific realists, in contrast, have to be more ambitious, especially if they are to avoid the charge that multiple projectability is simply superficial or even a deceptive feature. In this vein, Ruth Millikan contends that Real Kinds are richly projectable due to some natural ground (2000, p. 18). Michael Devitt in the same vein argues that generalizations about the morphology, physiology, and behavior across members of a species demand an explanation: "Why are they so?" (2008, p. 352).

This then leads us to the second role of essential natures observed by both Putnam and Kripke: they offer a deeper explanans. More precisely, essential natures causally explain the inductive unity across dimensions of similarity and systematic variation displayed by members of a Kind. For scientific realists at least, discovering a Kind's essential nature would thus not only be a matter of providing (improved) grounds for individuation and scope of inductive inference, but also a matter of explaining why it is that members of a Kind jointly achieve a certain reliable inductive structure. Essences should explain the Kind's multiple projectability.

A good question at this point is: what is the relationship between these respective roles of essences? Samir Okasha has pointed out that there is no a priori reason to assume that something can or even should both individuate and explain Kind membership (2002, p. 203f.). In other words, we need not assume that the essence, in the sense of providing the grounds for individuation, should also be able to causally explain multiple projectability (and vice versa). As we shall see in the succeeding sections, both Okasha and Devitt also offer some reasons for thinking the roles come apart in the case of species. 
While my argument does not require an a priori assumption in what follows, I would like to submit some initial reasons to think that the two basic roles of essences do in fact come together in a unified account, which will also be born out it in the proceeding argument. First, it seems plausible to me that the capacity of providing explanations of multiple projectability is what gives us reason to think that a property is, in fact, an essence of the Kind in the first place. It is hard to see how one can provide the identity and call something the essential nature of a Kind, if it did not also have some special explanatory import or power vis-à-vis other properties that belong to a Kind (Kung 1977). ${ }^{6}$ Moreover, at least for scientific realists, it seems like the empirical enquiry into the structures causally responsible for (and hence, explanatory of) the projectable features should also have a bearing on the individuation conditions of the Kind. ${ }^{7}$ There is also an argument for a unified account from the other direction: to explain a Kind's multiple projectability one seems to rely on some individuation condition in the first place. That is, a causal explanation is also constrained by the fact that they apply to all members of the Kind. If they were only applicable to, say, a subclass of members of the Kind, it is unclear how the explanation would also explain the Kind's multiple projectability - a characteristic that is essentially distributed amongst all and only all members. Accepting these arguments would mean that although we can separate the two roles of essential natures at a conceptual and epistemic level, from an ontological and empirical perspective the essence of a Kind is one and the same thing.

\section{The historical essential natures of species}

\subsection{Individuation}

Linnéan binomial nomenclature attained some inductive success by organizing organisms into species within nested categories. Though some species have been reorganized, many of the species noted by von Linné are still recognized by the best current

\footnotetext{
${ }^{6}$ I thank Ville Paukkonen for pointing me toward some interesting historical precedents to the discussion of the two roles of essences. Pasnau (2004), for instance traces two similar roles in Aristotele's philosophy of substantial forms; namely, first, to give an abstract characterization of what a particular substance is, and thus to provide the identity of the Kind, and second, especially important to the scholastics, a more concrete role to explain the natural effects of a substance. My own argument about the interconnections between these roles here draws heavily on Joan Kung's interpretation of Aristotle: "Aristotle also makes it clear that the properties which belong essentially to anything have explanatory power vis-à-vis the other properties of things of that kind. This is no mere fortunate accident. The fact that a property had explanatory power is given as a reason for counting it essential to a thing and the fact that a property lacks 'explanatory power' rules out the property belonging essentially to the thing under consideration"(1977, p. 370).

${ }^{7}$ Not all avowed realists seem to think the investigations into the causal structure gets us all the way to a membership criteria. According to Richard Boyd's homeostatic property cluster (HPC) account, (1991, 2010) there can be multiple sources of the same clustering. Hence homeostatic mechanisms can uphold, but do not wholly individuate, the clusters. In Matthew Slater's recent stable property cluster (SPC) account (2015), Kinds are simply defined in terms of the cliquish existence of stable, but not wholly uniform, property clusters. Hence neither account provides a causal explanation of clusters that also individuates the Kind in question. As Thomas Reydon has argued, these accounts therefore fall short in guiding predictions or scope of the inductive inferences connected to the Kind (2009). In lieu of some other way to individuate Kinds or determine membership, I therefore think it is doubtful how far the scientific realism of both the SPC and HPC accounts goes.
} 
classificatory systems. At the same time, binomial nomenclature did not provide much of a systematic basis for its taxonomic order. After Darwin, this would change decisively when he proposed that common descent was an explanation for nested taxa. This insight was carried through in the subsequent work in species classification within the Modern Synthesis, represented by figures like Theodosius Dobzhansky, George Simpson, and Ernst Mayr and the rise of phylogenetics.

In the preceding section, I suggested that a promising way for a scientific realist to account for the developments after Darwin is that the right individuation conditions behind the intuitive biological taxonomic categories were uncovered by gradually revealing a causal explanatory basis for it-or, in short, one that has to do with discovering the essential natures of species. In fact, Darwin and many of the authors of the Modern Synthesis appear to have been in disagreement about the nature of species and what's more, it's arguable that they were anti-essentialists (Godman 2019). Nevertheless, I will argue that with the help of a historical relation uniting a species, a scientific realist does have essential natures at their avail that can both individuate as well as explain the multiple projectable properties associated with these biological Kinds. It is to this task I now turn, beginning with individuation.

At least at first pass, the individuation criterion follows straightforwardly: an organism belongs to a species taxon in virtue of its spatial-temporal location in the tree of life. ${ }^{8}$ The essence of a species taxon is then the particular historical relation that unites its members. As we shall see, the historical relation is not any old relation or relational property: at first approximation it consists of a unique lineage of spatially and temporally ordered individuals. As we are in search of the individuation criteria, we might bracket questions about the scale and mechanisms by which such lineages are formed until the next section on causal explanations. The key here is to appreciate how the historical relation of a lineage individuates; how it is essential to the individual member of a species taxon, in the sense that it is a relation (or relational property) that an instance could not lose without also ceasing to be a member of that particular taxon. The essence has the modal force of being a necessary property of the Kind. ${ }^{9}$

The knowledge of the historical essences is a posteriori twice over. First, the fact that species have historical essential natures is an a posteriori matter (something which Darwin and others helped establish). Second, specific lineages of species are known a posteriori. As we cannot directly observe lineages, the latter is primarily established with the use of cladistics and phylogenetic methods for reconstructing lineages. It is important to stress that phylogenetics makes no a priori assumption about

\footnotetext{
8 To be more cautious, I would say tree of speciation rather than of life as I have some reservations about whether prokaryotes like various forms of bacteria due to pervasive lateral transmission can constitute reproductive lineages or even lineages, although they are clearly living organisms and biological Kinds (see e.g. Doolittle 1999).

9 A word about the possibility of swamp tigers and related thought experiment: on the historical-relational account, I believe the right thing to say is that there is a genuine metaphysical possibility of swamp individuals that resemble tigers. Yet these individuals are not members of the species taxon, Panthera Tigris. Because they do not share a lineage of historical reproduction with other tigers, this also implies that we are not licensed to assume that they are multiply projectable along with others tigers. This is true however many similarities are noted amongst "swamp tigers" and real members of the historical Kind, Panthera Tigris, simply because they do not share an essence in common. Hence accepting the metaphysical possibility of individual swamp tigers does not violate the Kind individuation criteria of the historical essentialist account.
} 
the spatial-temporal relationships between different species; instead phylogenies are constructed based on different methods of producing data, either on morphological evidence or, more commonly, molecular evidence of DNA and RNA sequences.

With the assumption that convergent evolution is rare, two species with a greater number of shared characters from either of these domains is taken as evidence of them having more recent common ancestry compared to two species with fewer shared characters. Individuals are then grouped together into monophyletic groups at particular nodes, either by a speciation event (typically branching) or a terminal node. Moreover the increasing work in computational phylogenetics-explicitly designed to not confirm pre-existing assumptions of phylogenetic relationships-is regarded as further support for hypotheses concerning branching relationships.

I take this to be a form of'triangulation" of lineages or historical essences, where triangulation means that the robustness of the hypotheses about lineages and speciation are increased because of the decreased chance of error and bias when diverse and independent sources of evidence are employed (Kuorikoski and Marchionni 2016). The scientific realism espoused here just adds that such triangulation gets at the (approximately) correct structure that individuates different species. Such triangulation has also yielded some surprising and significant revisions to our initial classifications and membership criteria of taxa. Take the case of the critically endangered Christmas Island shrew, Crocidura attenuata trichura. To a casual observer, these tiny, beady-eyed, mole-like individuals look exactly like the North American shrew, but by triangulating evidence from different domains, we get a genealogical tree where the Australian shrew is, for instance, more closely related to the kangaroo than it is to the American shrew. This has consequences for the scope and structure of inferences we can make about the Kinds. The more we know about an individual's spatial temporal position in the tree of speciation (we may know the whole, a partial bit of the tree, or more commonly just the close ancestors and the descendants), the more we know about of which inferences are justified, including what conservation efforts might be deemed appropriate (Eldridge et al. 2014). At the same time the use of diverse and independent sources of evidence in lineage reconstruction reduces the probability of systematic errors and biases.

So although uncovering lineages is dependent on tracking intrinsic traits of individuals as well as on auxiliary hypotheses tied to specific phylogenetic methods, this should not make us skeptical of objective lineages. On the contrary, the use of triangulation should strengthen our confidence in scientifically progressive knowledge of the tree of branching species. With triangulation we can empirically and consistently move toward improved individuation criteria of a species; triangulation takes us beyond a series of classifications according to convention.

Authors skeptical of the epistemic credentials of historical essences would at this point dig in their heels claiming that historical essences are not sufficient for the purposes of individuating species taxon. For instance, Michael Devitt alleges that the historical account would not be able to distinguish "a species from the species that preceded and succeeded it in its lineage" (2008, p. 367).

First it might be useful to manage expectations a bit by conceding the limits of essential natures of particular Kinds. For one, it is not clear that they should be able to sort out all higher-order questions about what makes a particular Kind a species (rather 
than, say, a higher class or a subspecies)—what is sometimes known as the species category problem. After all, analogous higher order or contrastive questions can be posed for most, if not all, putative Kinds that figure in scientific taxonomies. That is, in chemistry we can ask not only what makes a sample a member of magnesium, but also, what makes it a chemical element; or, in the case of gender, we can ask, not only what makes someone a women, but also, what makes someone belong to a certain gender (as opposed to another social kind, e.g. sexuality)? In these cases it is not quite clear that membership conditions of the first order will be informative of the higher order contrastive questions. I am afraid my concern here is limited to providing the criteria of identity of particular Kinds commonly understood to be species, such as humans (Homo sapiens), Christmas Island shrew (Crocidura attenuata trichura) and African bush elephant (Loxodonta africana). I have argued that an individual's membership in either of these Kinds is determined by its place in a spatial-temporal order of individuals; i.e. by its historical relation or relational property. I do not take myself to be offering an argument as to whether these Kinds are truly species rather than biological Kinds of a different sort. Such higher-order or contrastive questions probably deserve a separate treatment. In the case of species, answers are probably going to hinge on debates about typical patterns of speciation (gradual or defined by punctuated equilibrium) and typical causes of speciation events and new ancestral populations (e.g. are mechanisms of reproductive isolation or hybridization barriers required for speciation and the acquisition of relevant adaptations, or do we need to add an asexual equivalent mechanism, like the competition for living spaces). ${ }^{10}$ What I will say is that these and other debates are best made sense of on the assumption of an underlying conceptual unity where a necessary property of a species taxon is still its historical essence (De Queiroz 1999). That also means that reproductive isolation can be understood as evidence of species differentiation rather than a necessary property for species membership (De Queiroz 2007, p. 882).

Still Devitt might insist that his concern is a first-order matter and not only a higher order one about the species category. The thought seems to be the following: We need a sufficient criteria in addition to the necessary historical lineage to individuate the Kind which members belong to; otherwise we will not have a way of determining when an ancestral population is formed and when the lineage commences. In short we will not be able to mark out a biological Kind from the one that immediately precedes it—regardless of whether these Kinds are truly species or not. Devitt continues to press this type of concern in favor of adopting a biological intrinsic essentialism (2008, 2010; see also Elder 2008). LaPorte (2005) instead suggests that this concern should leads us to some form of historical conventionalism, since non-epistemic political criteria might be introduced to decide things like whether Neanderthals (Homo neanderthalensis)

\footnotetext{
10 For the reasons mentioned in footnote 7 where some groups of organisms, like bacteria (commonly thought to be species) may not form reproductive lineages, I am also open toward a pluralism about the species category. Notice that endorsing such a position, however, does not lead to pluralism about particular species or indeed scepticism toward individual species having definite lineages. As Joseph LaPorte writes:"Suppose that the species category is disjunctive, because some species are reproductively united and others are ecologically united. This would not indicate that any one species-a species of oaks, say-has a disjunctive essence. It would not. That species' essence would be ecological, not ecological OR reproductive. Individual lineages like the different oaks or like H. sapiens would remain integrated and natural biologically, united by one measure or the other for species" (2017, p. 190).
} 
is really a distinct species from Homo sapiens. For LaPorte then, there really is no such thing as an "objective evolutionary tree of life" (however see LaPorte 2017 for a suggestion that he now favors a historical essentialism of species).

Notice first that a conventionalism does not simply follow from the existence of disagreement about politically controversial cases of branching. It is still open for scientific realists to argue that with respect to individuation conditions of a majority of different species like, Homo sapiens, Christmas Island shrew (Crocidura attenuata trichura) and African bush elephant (Loxodonta Africana) scientific progress has been made. A shared historical relation or historical essence has been established or is in the process of being established via triangulation: data has been gathered to trace a relevant historical essences through phylogenetics and cladistics and finally some branching events have been hypothesized which have a higher degree of support.

Still, many have with Devitt supposed that even with the appeal to objective branching events with higher degrees of support, historical essentialism does at least need to be supplemented with some form of origin essentialism (see e.g. Hull 1978; Griffiths 1999; Okasha 2002). In addition to having a unique spatial temporal relation, each Kind of species would then also have a particular origin that is essential to the Kind. But I think there is a compelling argument that there needs not be such an appendage. Marc Ereshefsky has recently suggested that a historical essentialist can also embrace speciation as a path dependent process where the origin is an unnecessary addition (2014). The notion of path dependency will be elaborated upon in the next section, but for now the idea is simply that speciation is not merely a matter of mutations for new adaptations (and perhaps, reproductive isolation) occurring, but also a matter of a specific order and pathway of events, such as the temporal order of mutations. If the order of mutations were reorganized, speciation may in fact not have occurred (Beatty 2006).

So according to Ereshefsky, it is rather the other way around: the whole idea of an origin or a starting point for a species demands that an historical pathway has already been underway:

If one looks at the branching event at the time it occurs, a species' identity is not determined (ontologically) because the existence of that species is not yet established. Further along the historical path of the branch, we can retrospectively say that the new species began at the branching event [...] If we want to talk about a species' essence in a historical sense, then that essence must be a species' origin plus its unique path. But in that case, the notion of origin is redundant: the idea of a unique path assumes a starting point. (2014, pp. 724-725)

I think this argument from Ereshefsky is compelling; the necessary and sufficient criteria for individuating species Kinds is already part and parcel of their historical essence. If a particular path dependent process constitutes a speciation, then that is the essence and origin essentialism is simply unnecessary to individuate the Kind. One might also think that we should not even aim to ascertain any starting-points or branching events because such events are extended in time and are complex and often vague. ${ }^{11}$ No matter for the historical essentialist: as long as an individual gains

\footnotetext{
${ }^{11}$ I thank an anonymous reviewer from this journal for making this possibility salient to me. In fact, when pressed most authors accept some degree of vagueness with respect to the starting-point and branching
} 
its Kind membership via its involvement in the particular historical lineage, scientific progress in tracking this unique path is possible, regardless of how we conceive of the path's beginning.

\subsection{Causal explanation}

Perhaps the chief concern about importing a historical essentialism into a defense of scientific realism concerns their ability to satisfy the causal explanatory role of essences. A common view is that in order to perform the role of causally explaining the common traits of a species or a Kind, one must refer to intrinsic features of individual members. Samir Okasha argues for this assumption as follows:

If members of a kind $\mathrm{K}$ share only a relational property that means they may differ widely with respect to intrinsic properties. But since an object's causal propensities are usually thought to supervene on its intrinsic properties alone, $\mathrm{K}$ will include only those objects whose causal propensities are very different, which means that predictively useful generalizations are unlikely to exist. (2002, p. 208)

Of course, a central assumption of this paper is that despite intra-species variation, a species does support at least some important causal generalizations across their members (in terms of physiology, morphology, habitats, mating patterns etc.). This is all part of the explanandum to which our causal explanans should be tailored. Hence, the aim of the next section is to show that although many-but not all-of the causal propensities of the individual/object do in fact supervene on members' intrinsic features, it is nevertheless the historical essences of species that offer causal explanations of the Kind's inductive unity or multiple projectability. In passing I will also challenge Okasha's assumption that causal propensities supervene on intrinsic properties alone. At least many behavioral phenotypes also supervene on extrinsic-environmental-properties of the organism.

Some initial plausibility of this explanatory claim has already been rehearsed. In Sect. 2, I suggested that the intuitive support for a historical essence providing the identity of a Kind might actually derive from its explanatory power. That is, I proposed that there are good reasons to think that there is an intimate connection between the individuation condition and explanatory condition such that it is the explanatory power of a property or relation that gives us reason to think that it individuates the Kind in the first place. If so, any success of historical essences as grounds for individuating a species might already ride on their ability to explain what I have referred to as the species' multiple projectability — a quality that is essentially distributed over a Kind's members. In the last section, I argued that historical essences satisfy the individuation condition by being the property that is uniquely shared amongst all members; it is the necessary property, which an individual cannot lose without also ceasing to be a member of a species taxon. The argument that historical essences were also sufficient

Footnote 11 continued

event of different lineages. Michael Devitt for example writes: "[E]veryone agrees that there comes a point where two organisms that have some common ancestor are nonetheless of different species. Yet there is no determinate matter of fact about precisely where that point is". (2008, p. 373, emphasis in original). 
rested on the appeal of path dependent, temporally ordered, explanations of branching events. If we accept this argument it would seem like the individuation conditions do in part rest on the ability historical essences and path dependency have to explain.

The task now is to argue for the explanatory role of historical essences more directly. An initial pessimism toward historical essences-especially amongst scientific realists-stems not from an apparent lack of explanatory power per se, but from the view that historical explanations constitute nominal or conventional explanations, rather than causal explanations. As is well known, David Hull was one of the early and prominent proponents of species as historical entities (1978). ${ }^{12}$ What is probably less well known in these debates is his general defense of the explanatory credentials of historical narratives. For Hull historical narratives are a species of explanation-integrationist explanations - that go via integrating an event into an organized whole (1975).

Of course here we are not concerned with explaining events as much as the emergence of a Kind with a distinctive inductive unity. Still, much of the same virtues of historical explanations in biology have been emphasized in Desjardins (2011) and Ereshefsky's $(2012,2014)$ recent work on path dependent explanations where it is precisely the properties of different biological Kinds such as species and homologues that are explained by citing their historical structure. All authors stress that integrationist or path dependent explanations do not conform to a Hempel-style covering law model of explanation or a Salmon-style causal model of explanation, which require that an initial condition and an inference-maker (a law or causal generalization) are cited. For integrationist or structural explanations, it would also be insufficient to cite the initial causal state or origin of a species (e.g. last common ancestor or source of novel adaptations etc.). Historical explanations are path dependent in a strong sense by including all relevant causal factors and their order relevant to the explanandum (Ereshefsky 2012, 2014). Perhaps because of the contrast with the covering law and causal models, Hull also wavers about the causal nature of these part-whole explanations suggesting that the historical relation between the parts of a lineage is one of constitutive dependence between the parts, their sequence of organization, and the whole. Of course some integrationist explanations are probably not causal, but constitutive explanations, like that of a decomposition of a mechanism into its constitutive parts. But it does not follow that at least some integrationist historical explanations cannot qualify as causal explanations.

The notion of path dependency allows us to adopt two perspectives on the historical essences of species. The one argued for in Sect. 3.1 is that of individuation: an exclusive and distinctive spatial-temporal pattern belonging to a particular species taxon (that is, of the different evolutionary pathway each species taxon has, in fact, taken). But as discussed, in order to access this historical pattern one also has to incorporate causal evidence (e.g. evidence of homologous rather than analogous traits and evidence of reproductive isolation). From the perspective of path dependent explanations it then seems just as legitimate to regard phylogenetics as a means of tracing a token causal process. Indeed these perspectives can be seen as two sides of the same coin. The

\footnotetext{
12 Of course Hull argued that species are individuals rather than, sets, classes or, indeed, Kinds. For present purposes I accept that there is no tension between thinking a species taxon can be both an individual and a Kind with a historical essence (for arguments see, Griffiths 1999; Millikan 2000; Rieppel 2007).
} 
pattern of spatially-temporally ordered members of a species taxon do not come about through some pre-established harmony; the pattern comes about through a range of causally connected events.

Having established that historical path dependency qualifies as a bona fide causal explanation, we are at a point to see why historical essences causally explain multiple projectability specifically. They explain in virtue of the nature and order of causally connected events. Compare the lineage or pathway of a species with that of a timeline. The latter can be thought of a useful representation of a purely temporal sequence of events. But it can also be misleading: temporally ordered events of a timeline need not have any particular causal relation with one another or with an overall outcome. In contrast, the spatial-temporal pattern of a lineage is useful not merely as it orders events temporally (and spatially); if it is correct, or approximately so, it also reveals a particular causal pathway of organisms coming about and at the same time retaining projectable features with their ancestors. Past members both produce new members and reproduce features of the species. That is, by bringing new organisms about, past members also ensure that they share properties with their ancestors. This reproductive connection between different members is why a historical essence explains a Kind's multiple projectability — why it is that members of a Kind jointly achieve a certain reliable inductive structure.

On closer examination then, historical essentialism of a Kind such as a particular species demands some reproductive or near reproductive relation. ${ }^{13}$ Only then can we causally explain why members share multiple features with one another because of their history. If one were to overlook the significance of reproduction, one might agree with Muhammed Khalidi's view that historical Kinds also occur in chemistry. Khalidi gives the example of most helium- 4 in the universe being created by the past combination of two helium-3, a nuclei reaction that emits 2 protons (2013, p. 139). But Kinds like different species have historical essences in a much stronger sense. It is not merely that there can be or often is a causal contact with previous members, but that there must be-a new token member must be born of previous members (or in boundary cases, closely related ancestors). Otherwise the historical pathway would also cease to be explanatory of the Kind's multiple projectable properties.

The causal path dependency also bestows the explanation of multiple projectability with counterfactual force. If there had been different causal factors and a different temporal or spatial order of events along the way, the species' lineage would also have been different and different projectable properties would have been associated with it. In fact, historical explanations might seem maximally sensitive to counterfactual change. That is, had any part of history been different, the species would also have been a different one from the one it actually is. However, though the historical pathway certainly confers a significant counterfactual force to the explanation, we must also keep the explanandum in mind; namely, the species' distinctive multiple projectability. Not all events in its pathway will therefore affect the Kind's distinctive inductive structure and need to figure in the explanans. Some relatively minor events in the course of the lineage will be included in the explanans, such as an organism's retention

\footnotetext{
13 There might be some ecological mechanism that is sufficient for forming lineages of species, but I will not explore this here-see e.g. LaPorte (2017).
} 
of a novel mutation in response to a changing niche; other events, such as, presumably, some still births, may have no bearing on the overall multiple projectability and so can safely be excluded from the explanans. It follows that they will not affect the identity of the species either. Equally, the relevant multiple projectability can subsume traits that were also present prior to the evolution of a particular species, but the casual historical explanation will then not include the emergence of such traits, but only their retention within the lineage.

Once we regard historical essences as token causal processes in their own right, we can also ask for a causal productive explanation of those processes. Now we have a different explanandum in mind: what forms of causal interaction forge the reproductive bonds of Kinds with historical essential natures? ${ }^{14}$ In the case of species, the explanans would presumably draw on proximate mechanisms for the production of new members and the retention (and systematic variation) of traits amongst particular species taxon members. Recent work in epigenetics and niche constriction theory, suggest we should then also go beyond the intrinsic properties of organisms in our explanans. That is, causal mechanisms that are extrinsic yet proximate to the organism can also contribute to the stability of many traits, either by being a condition for successful reproduction of traits, reproducing traits on their own, or by weeding out deleterious mutations.

Note however that this does not make the conjunction of proximate reproductive mechanisms rival explanations to historical essences. To be clear, the historical essence qua token causal process still causally explains the presence of multiple projectable properties associated with different species. However there is a closely related explanatory project about what proximate causal features produce the reproductive links of Kinds like species. These proximate mechanisms are nonetheless non-essential to the Kind, especially as they may vary amongst individuals and over the course of a species' lineage. Hence, pace Devitt, they are not able to offer rival intrinsic accounts of the essence of a species (see also Godman and Papineau (2019) for an explicit argument for why a historical-reproductive explanation is not only independent of, but also superior to, Devitt's intrinsic essentialism). Nor has the explanatory buck been passed to more proximate features of the organisms; the explanandum in this case has simply changed. ${ }^{15}$

We now have an improved response to Okasha's concern mentioned in the beginning of this section. It is of course true that if members were to differ greatly with respect to intrinsic properties it would be strange to think they would nevertheless share many morphological and behavioral properties. But if we take historical essences of species to be an explanandum, we can see why the intrinsic properties may vary but will, in fact, not vary greatly amongst members. This is because they are realized by many of

\footnotetext{
14 For an instructive discussion of how to formulate an account of reproduction that does not bias us toward gene flow as the paradigm of reproduction (see Godfrey-Smith 2009, Ch. 4).

15 Notice that the explanations here-i.e. one that asks to explain the presence of multiple projectability and the other that asks about the production of reproductive links (or in indeed, the production of individual traits of species) - is not the same as the distinction between proximate and ultimate explanations (Mayr 1961). I am not persuaded that the notion of essence has much work to do in connection with the Mayr's question about evolutionary history. I have argued that talk of essences earns its keep when we need to explain a body of generalizations of Kinds such as different species, rather than single traits of a Kind (see also Godman and Papineau (2019)). I thank and anonymous reviewer for pressing me on this point.
} 
the same proximate causal feature or mechanisms in individual members' development and life span. It is just that we are liberated from the straightjacket of claiming that these features are essential to the species. In sum, it should no longer be a mystery how species are able to support causal generalizations despite having "only" historical essences.

\section{Conclusion}

I have argued that species have historical essences in ways that should matter for those interested in the nature of species and for those wishing to defend scientific realism in the non-fundamental sciences. For those interested in the debate about the nature of species, my aim has been to provide stronger support for the idea that species have historical essential natures by demonstrating their hitherto underestimated credentials in terms of individuation and explanation. For scientific realists, I have wanted to give a better sense of why a posteriori essential natures, and historical essences in particular, are suitable companions to scientific realists in biology and other "historical sciences" (Millikan 1999). I have made this case by showing how in the paradigm case of species, historical essential natures do yield robust individuation and membership criteria as well as causal explanations of multiply projectable features. Moreover, we have seen that the notion of path dependency inherent in historical essences adjoins individuation with explanation. While the scope for applying similar defenses for other putative historical Kinds remains for another day, at least the principled resistance to such a defense has hopefully been cleared.

Acknowledgements I would like to thank audiences at the various conferences and seminars at which drafts of this paper have been presented and to the anonymous reviewers of this journal. I am particularly indebted to David Papineau and Ville Paukkonen for careful readings and insightful comments.

Open Access This article is distributed under the terms of the Creative Commons Attribution 4.0 International License (http://creativecommons.org/licenses/by/4.0/), which permits unrestricted use, distribution, and reproduction in any medium, provided you give appropriate credit to the original author(s) and the source, provide a link to the Creative Commons license, and indicate if changes were made.

\section{References}

Bach, T. (2012). Gender is a natural kind with a historical essence. Ethics, 122(2), 231-272.

Beatty, J. (2006). Replaying life's tape. Journal of Philosophy, 103, 336-362.

Bird, A. (2007). What is scientific progress? Nô̂s, 41(1), 64-89.

Boyd, R. (1991). Realism, anti-foundationalism and the enthusiasm for natural kinds. Philosophical Studies, 61(1), 127-148.

Boyd, R. (2010). Realism, natural kinds, and philosophical methods. In H. Beebee \& N. Sabbarton-Leary (Eds.), The semantics and metaphysics of natural kinds (pp. 212-234). New York: Routledge.

Churchland, P. M. (1985). Conceptual progress and word/world relations: In search of the essence of natural kinds. Canadian Journal of Philosophy, 15(1), 1-17.

De Queiroz, K. (1999). The general lineage concept of species and the defining properties of the species category. In R. Wilson (Ed.), Species: New interdisciplinary essays (pp. 49-89). Cambridge MA: MIT Press.

De Queiroz, K. (2007). Species concepts and species delimitation. Systematic Biology, 56(6), 879-886. 
Dennett, D. C. (1991). Real patterns. The Journal of Philosophy, 88(1), 27-51.

Desjardins, E. (2011). Historicity and experimental evolution. Biology and Philosophy, 26, 339-364.

Devitt, M. (2008). Resurrecting biological essentialism. Philosophy of Science, 75(3), 344-382.

Devitt, M. (2010). Species have (partly) intrinsic essences. Philosophy of Science, 77(5), 648-661.

Doolittle, W. Ford. (1999). Phylogenetic classification and the universal tree. Science, 284(5423), 2124-2128.

Elder, C. (2008). Biological species are natural kinds. Southern Journal of Philosophy, 46, 339-362.

Eldridge, M. D., Meek, P. D., \& Johnson, R. N. (2014). Taxonomic uncertainty and the loss of biodiversity on Christmas Island, Indian Ocean. Conservation Biology, 28(2), 572-579.

Ellis, M. W. (2011). The problem with the species problem. History and Philosophy of the Life Sciences, 33(3), 343-363.

Ereshefsky, M. (2012). Homology thinking. Biology and Philosophy, 27(3), 381-400.

Ereshefsky, M. (2014). Species, historicity, and path dependency. Philosophy of Science, 81(5), 714-726.

Ereshefsky, M., \& Matthen, M. (2005). Taxonomy, polymorphism, and history: An introduction to population structure theory*. Philosophy of Science, 72(1), 1-21.

French, S. (2011). Shifting to structures in physics and biology: A prophylactic for promiscuous realism. Studies in History and Philosophy of Science Part C: Studies in History and Philosophy of Biological and Biomedical Sciences, 42(2), 164-173.

Godfrey-Smith, P. (2009). Darwinian populations and natural selection. Oxford: Oxford University Press.

Godman, M. (2015). The special science dilemma and how culture solves it. Australasian Journal of Philosophy, 93(3), 491-508.

Godman, M. (2018). Gender as a historical kind: A tale of two genders? Biology and Philosophy, 33(3-4), 21.

Godman, M. (2019). A modern synthesis of philosophy and biology. In K. Becker \& I. Thomson (Eds.), History of philosophy, 1945 to 2015. Cambridge: Cambridge University Press. (forthcoming).

Godman, M., Mallozzi, A., \& Papineau, D. (under consideration). Essential natures are super-explanatory: Taming metaphysical modality.

Godman, M., \& Papineau, D. (2019). Species have historical not intrinsic essences. In A. Bianchi (Ed.), Language and reality from a naturalistic perspective: Themes from Michael Devitt. Springer Press. (forthcoming).

Gould, S. J. (1986). Evolution and the triumph of homology, or why history matters. American Scientist, 74(1), 60-69.

Griffiths, P. E. (1999). Squaring the circle: Natural kinds with historical essences. In R. Wilson (Ed.), Species: New interdisciplinary essays (pp. 209-228). Cambridge MA: MIT Press.

Hacking, I. (2007). Natural kinds: Rosy dawn, scholastic twilight. Royal Institute of Philosophy Supplement, 61, 203-239.

Häggqvist, S. (2005). Kinds, projectibility and explanation. Croatian Journal of Philosophy, 5(13), 71-87.

Hull, D. L. (1975). Central subjects and historical narratives. History and Theory, 14, 253-274.

Hull, D. L. (1978). A matter of individuality. Philosophy of Science, 45(3), 335-360.

Khalidi, M. A. (2013). Natural categories and human kinds: Classification in the natural and social sciences. New York: Cambridge University Press.

Kincaid, H. (2000). Global arguments and local realism about the social sciences. Philosophy of Science, 67, S667-S678.

Kornblith, H. (1995). Inductive inference and its natural ground: An essay in naturalistic epistemology. Cambridge: MIT Press.

Kripke, S. (1980). Naming and necessity. Harvard: Harvard University Press.

Kung, J. (1977). Aristotle on essence and explanation. Philosophical Studies, 31(6), 361-383.

Kuorikoski, J., \& Marchionni, C. (2016). Evidential diversity and the triangulation of phenomena. Philosophy of Science, 83(2), 227-247.

LaPorte, J. (2005). Is there a single objective, evolutionary tree of life? The Journal of Philosophy, 102(7m), 357-374.

LaPorte, J. (2017). Modern essentialism and its animadversions. In R. Joyce (Ed.), The Routledge handbook of evolution and philosophy (pp. 182-193). Abingdon: Routledge Press.

Lewens, T. (2012). Species, essence and explanation. Studies in History and Philosophy of Science Part C: Studies in History and Philosophy of Biological and Biomedical Sciences, 43(4), 751-757.

Magnus, P. D. (2011). Drakes, seadevils, and similarity fetishism. Biology and Philosophy, 26(6), 857-870. Mallozzi, A. (2018). Two notions of metaphysical modality. Synthese, 2018, 1-22. 
Massimi, M. (2014). Natural kinds and naturalised Kantianism. Noûs, 48(3), 416-449.

Mayr, E. (1961). Cause and effect in biology. Science, 134(3489), 1501-1506.

Mill, J. S. (1872). A system of logic: Ratiocinative and inductive (8th ed.). London: Longman.

Millikan, R. G. (1999). Historical kinds and the "special sciences". Philosophical Studies, 95(1), 45-65.

Millikan, R. G. (2000). On clear and confused ideas: An essay about substance concepts. Cambridge: Cambridge University Press.

Okasha, S. (2002). Darwinian metaphysics: Species and the question of essentialism. Synthese, 131(2), $191-213$.

Pasnau, R. (2004). Form, substance, and mechanism. The Philosophical Review, 113(1), 31-88.

Putnam, H. (1975). The meaning of 'meaning'. In Mind, language and reality, philosophical papers (Vol. 2, pp. 215-272). Cambridge: Cambridge University Press.

Reydon, Thomas A. C. (2009). How to fix kind membership: A problem for HPC theory and a solution. Philosophy of Science, 76(5), 724-736.

Rieppel, O. (2007). Species: Kinds of individuals or individuals of a kind. Cladistics, 23(4), 373-384.

Simpson, G. G. (1951). The species concept. Evolution, 5(4), 285-298.

Slater, M. (2015). Natural kindness. British Journal for the Philosophy of Science, 66(2), 375-411.

Snyder, L. J. (2005). Confirmation for a modest realism. Philosophy of Science, 72(5), 839-849.

Wilson, R. A. (1999). Realism, essence, and kind: Resuscitating species essentialism? In R. Wilson (Ed.), Species: New interdisciplinary essays (pp. 187-207). Cambridge MA: MIT Press.

Publisher's Note Springer Nature remains neutral with regard to jurisdictional claims in published maps and institutional affiliations. 